Check for updates

Cite this: RSC Adv., 2020, 10, 35121

Received 7th September 2020

Accepted 14th September 2020

DOI: 10.1039/dOra07665a

rsc.li/rsc-advances

\section{Spectroscopic and chromatographic investigation of chiral interactions between tiaprofenic acid and alginate-metal-complexes $\uparrow$}

\begin{abstract}
Ghaidaa Alkhayer, (D) *a Hussein Khudr ${ }^{\mathrm{b}}$ and Yahia Koudsi ${ }^{\mathrm{a}}$
Alginate-metal-complexes of $\mathrm{Ca}, \mathrm{Ba}, \mathrm{Zn}, \mathrm{Fe}$ and $\mathrm{Al}$ were prepared in the form of beads. The preparation was based on the ionotropic method to obtain blank beads (unloaded) and beads loaded with tiaprofenic acid. IR spectra of blank beads, drug loaded beads and physical mixtures of the drug with the blank beads were recorded. The comparison of these spectra, especially in the region of hydroxyl group, implied chiral interactions between the drug and the complexes. Additionally, the drug was released from the loaded beads in aqueous phosphate buffer solutions (PBS) at $\mathrm{pH}=7.4$. Chiral HPLC was used to determine the enantiomeric excess, \% ee, of the released drug. The determined \% ee values indicated chiral interactions between tiaprofenic acid and alginate-metal-complexes. However, various mathematical models were used to simulate the release kinetics for each enantiomer. The metal content of $\mathrm{Na}, \mathrm{Ca}, \mathrm{Ba}$, $\mathrm{Zn}, \mathrm{Fe}$ and $\mathrm{Al}$ in the studied materials was measured using atomic absorption spectroscopy.
\end{abstract}

\section{Introduction}

Chirality has influenced all areas of drug research, design, development, and applications. ${ }^{1-5}$ Recently, the global market growth of chiral drugs increased, and chiral materials have been used for enantioselective release purposes. ${ }^{6}$

Drugs are formulated with excipients in different ways to provide the required benefits. ${ }^{7}$ Currently, chiral excipients represent a substantial part of the commonly used excipients, and alginate has numerous pharmaceutical and medical applications among various chiral excipients. ${ }^{8-10}$

Tiaprofenic acid (Tia) (Fig. 1) is one important non-steroidal anti-inflammatory drug (NSAID) belonging to the 2-arylpropionic acid family. It is an analgesic and used to treat pain, especially arthritic pain. ${ }^{11}$ This chiral NSAID has two enantiomeric forms and is usually administrated as a racemate. The $S$-enantiomer possesses most of the beneficial anti-inflammatory activity, while the $R$-enantiomer has no significant chiral inversion..$^{12,13}$

The ionotropic congealing techniques of alginate have developed the use of this chiral excipient in the domain of delivery systems. ${ }^{14,15}$ These techniques are based on entrapping a drug within cross-linked networks resulted when a multivalent metal ion combines to the uronic acids in different alginate chains. These networks were characterized with "egg-box" structures. ${ }^{16,17}$

\footnotetext{
${ }^{a}$ Department of Chemistry, Faculty of Sciences, Damascus University, Syria. E-mail: Ghaidaa.S.AlKhayer@gmail.com

${ }^{b}$ Higher Institute for Applied Sciences and Technology, Damascus, Syria

$\dagger$ Electronic supplementary information (ESI) available: Spectra data. See DOI: 10.1039/d0ra07665a
}

In a previous work, ${ }^{18}$ as a part of our study on drug-excipient chiral interactions of 2-aryl-propionic acid derivatives, it was demonstrated that congealing alginate with various metal ions affected the enantioselectivity and the rate of released ketoprofen enantiomers in vitro. The present work aims to investigate the existence of chiral interactions between tiaprofenic acid and various kinds of alginate-metal-complexes, and hence, the subsequent effect on the release behaviour and kinetics of $R$ and $S$ - enantiomers in vitro.

\section{Experimental section}

\subsection{Materials}

Alginic acid sodium salt purchased from brown algae bioreagent, suitable for immobilization of microorganisms from Sigma-Aldrich. Racemic tiaprofenic acid was from Sanofi (Sanofi Chimie, France) 100.2\%, calcium chloride, iron chloride, aluminium chloride, barium chloride dehydrate and zinc chloride was obtained from Merck. All other chemicals and reagents used were of analytical grade or HPLC grade.<smiles>CC(C(=O)O)c1ccc(C(=O)c2ccccc2)s1</smiles>

Fig. 1 Chemical structure of Tia, asymmetric carbon labeled with *. 


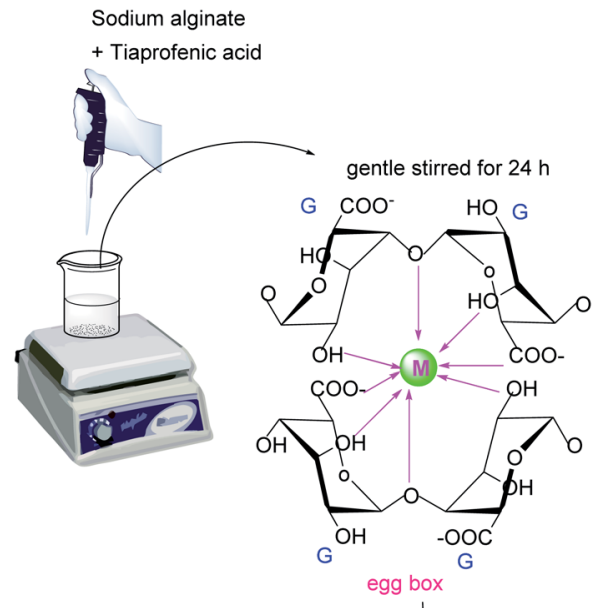

Beads separated and dried at $40 \mathrm{C}^{\circ}$ for $48 \mathrm{~h}$

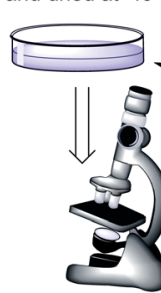

Optical microscope for imaging the surface of the beads

Fig. 2 The ionotropic congealing method of sodium alginate used to prepare drug-loaded and unloaded metal complexes beads. G: is the $\alpha$-L-guluronic acid blocks, $M$ : is the multivalent ion metal which binds to $G$ chains by a cross-linked network form with a proposed structure of "egg-box" model.

\subsection{Instrumentations and methods}

2.2.1. IR-spectroscopy. IR spectra of sodium alginate, blank alginate beads, loaded alginate beads, tiaprofenic acid and the corresponding physical mixtures of alginate beads and tiaprofenic acid were determined at a range $4000-400 \mathrm{~cm}^{-1}$ using $\mathrm{KBr}$ disk method (Bruker-vector 22). The samples were mixed with $\mathrm{KBr}$ and compressed at a pressure of 10 ton per $\mathrm{cm}^{2}$ using a hydraulic press.

2.2.2. Atomic absorption spectrophotometer (AAS). A certain amount $(6-10 \mathrm{mg})$ of each alginate beads sample were treated with $25 \mathrm{ml} \mathrm{HCl}$ at room temperature $1 \mathrm{~N}$. After $24 \mathrm{~h}$ and $48 \mathrm{~h}$ at room temperature, the obtained solutions were filtered and ready to measure the concentrations of $\mathrm{Na}^{+}, \mathrm{Ca}^{2+}, \mathrm{Zn}^{2+}$, $\mathrm{Ba}^{2+}, \mathrm{Fe}^{3+}, \mathrm{Al}^{3+}$. The metal ions contents in alginate complexes were determined using AAS-Shimadzu-AA6800 atomic absorption spectrophotometer.

2.2.3. HPLC. Tiaprofenic acid enantiomers were monitored using HPLC-LC-20AD Shimadzu-Japan, liquid chromatography equipped with photo-diode array detector, manual Rheodyne injector (model 7125, $20 \mu \mathrm{l}$ loop), and Lab solution software.

HPLC conditions were; isocratic, $1 \mathrm{ml} \mathrm{min}^{-1}$ flow rate of mobile phase containing hexane : isopropanol : TFA (90: $10: 0.1 \mathrm{v} / \mathrm{v} \%$ ). That mobile phase was degassed prior to use. The column, Kromasil@-5-amy- coat $(250 \times 4.6 \mathrm{~mm}$ i.d) 5 $\mu \mathrm{m}$, was equilibrated for at least $30 \mathrm{~min}$, at temperature $\left(30^{\circ} \mathrm{C}\right)$, with mobile phase flowing through the chromatographic system before starting the analysis. The samples were monitored at $254 \mathrm{~nm}$.

2.2.4. Alginate-metal beads preparation. Various types of alginate-metal complexes were prepared in form of beads via ionotropic gelation method as illustrated in Fig. 2. The prepared beads contained one metal ion and sometimes two metal ions. They also loaded with the drug and unloaded as a blank.

The blank beads were prepared by dissolving sodium alginate $(2 \% \mathrm{w} / \mathrm{v})$ in phosphate buffer solution (PBS), $\mathrm{pH}$ 7.4. After obtaining a clear bubble-free solution, it was droplets using a glassy tube (inner diameter of $1.0 \mathrm{~cm}$ ) into, the congealing bath, a solution of ion metal chloride $(3 \% \mathrm{w} / \mathrm{v})$ at room temperature. The tube was positioned at $5 \mathrm{~cm}$ above the surface of the metal chloride solution. The formed beads were gently stirred in the solution for $24 \mathrm{~h}$. After that, they were separated and washed with PBS, then with distilled water and dried at $40{ }^{\circ} \mathrm{C}$ for $48 \mathrm{~h}$.

However, alginate loaded beads were prepared by one-step; racemic tiaprofenic acid ( $\mathrm{Tia}$ ) with a ratio of ( 1 to $3.75 \mathrm{w} / \mathrm{w})$ to sodium alginate, was dissolved in (PBS, $\mathrm{pH} 7.4$ ), then, the obtained solution was congealed in the same manner as described above.

Alginate beads containing two metals were prepared by simultaneous and consecutive congealing, which was achieved by alerting the sequence and time of congealing conditions. Table 1 describes congealing conditions of all the prepared beads.

\subsection{Beads characterization}

The size of beads was measured using a ruler. The diameters were measured using at least ten beads. Table 1 shows obtained results. Optical microscope zoom 2000 from Leica microsystem, Germany was used for imaging the surface of samples. Photos of dried beads were taken with $\times 40$ magnification.

2.3.1. Drug loading and loading efficiency. To determine drug loading and loading efficiency, the following equations were used.

$$
\begin{gathered}
W_{\text {res }}=V \times C_{\text {res }} \\
\qquad W_{1}=W_{\mathrm{t}}-W_{\text {res }} \\
\text { Drug loading }(\mathrm{Tia} \%)=\left(W_{1} / \mathrm{W}_{\mathrm{db}}\right) \times 100 \\
\text { Loading efficiency } L(\%)=\left(W_{\mathrm{l}} / W_{\mathrm{t}}\right) \times 100 .
\end{gathered}
$$

where; $C_{\text {res }}$ is the concentration of residual Tia in congealing bath $\left(\mathrm{mg} \mathrm{ml}^{-1}\right), V$ is the volume of the solution $(\mathrm{ml})$, in our case $V=5 \mathrm{ml} . W_{\text {res }}$ is the residual drug weight in the congealing bath, $W_{\mathrm{t}}$ is the initial drug weight used for beads preparation and $W_{1}$ the quantity of a loaded drug. $W_{\mathrm{db}}$ is the total weight of dried drug loaded beads. The obtained results are summarized in Table 2.

2.3.2. Shrinkage ratio. The shrinkage ratio of the prepared beads was calculated according to the formula:

$$
S(\%)=\left(\left(D_{\mathrm{b}}-D_{\mathrm{a}}\right) / D_{\mathrm{b}}\right) \times 100
$$


Table 1 Some characteristics of prepared beads

\begin{tabular}{|c|c|c|c|c|c|c|c|}
\hline Type & Name & $\begin{array}{l}\text { Congealing } \\
\text { solution/time }\end{array}$ & & $\begin{array}{l}\text { Wet bead } \\
(\mathrm{mm})\end{array}$ & $\begin{array}{l}\text { Dry beads } \\
(\mathrm{mm})\end{array}$ & $\begin{array}{l}\text { Dry beads } \\
(\times 40)\end{array}$ & $\begin{array}{l}\text { Shrinkage ratio } \\
(S \%)\end{array}$ \\
\hline \multirow{5}{*}{$\begin{array}{l}\text { Tia loaded } \\
\text { alginate-metal beads }\end{array}$} & ACaT & \multicolumn{2}{|l|}{$\mathrm{CaCl}_{2} 3 \% 24 \mathrm{~h}$} & $5.8 \pm 0.8$ & $2.5 \pm 0.5$ & & $56.9 \pm 0.7$ \\
\hline & $\mathrm{ABaT}$ & \multicolumn{2}{|l|}{$\mathrm{BaCl}_{2} 3 \% 24 \mathrm{~h}$} & $5.8 \pm 0.8$ & $2.4 \pm 0.5$ & & $58.6 \pm 0.7$ \\
\hline & $\mathrm{AZnT}$ & \multicolumn{2}{|l|}{$\mathrm{ZnCl}_{2} 3 \% 24 \mathrm{~h}$} & $5.9 \pm 0.7$ & $2.8 \pm 0.6$ & & $52.5 \pm 0.7$ \\
\hline & AAlT & \multicolumn{2}{|l|}{$\mathrm{AlCl}_{3} 3 \% 24 \mathrm{~h}$} & $8.2 \pm 1.1$ & $3.3 \pm 0.5$ & & $60.4 \pm 0.8$ \\
\hline & AFeT & \multicolumn{2}{|l|}{$\mathrm{FeCl}_{3} 3 \% 24 \mathrm{~h}$} & $7.4 \pm 1.4$ & $2.8 \pm 0.4$ & & $62.2 \pm 0.9$ \\
\hline \multirow{3}{*}{$\begin{array}{l}\text { Tia loaded } \\
\text { alginate- mixed-metals beads }\end{array}$} & $\mathrm{A}_{1} \mathrm{~T}$ & \multicolumn{2}{|c|}{$\mathrm{CaCl}_{2} 3 \%+\mathrm{FeCl}_{3} 3 \% 24 \mathrm{~h}$} & $8.6 \pm 1.1$ & $3.2 \pm 0.9$ & & $62.8 \pm 1.1$ \\
\hline & $\mathrm{A}_{2} \mathrm{~T}$ & $\mathrm{CaCl}_{2} 3 \% 3 \mathrm{~h}$ & $\mathrm{FeCl}_{3} 3 \% 21 \mathrm{~h}$ & $6.6 \pm 0.5$ & $2.8 \pm 0.6$ & & $57.6 \pm 0.5$ \\
\hline & $\mathrm{A}_{3} \mathrm{~T}$ & $\mathrm{FeCl}_{3} 3 \% 3 \mathrm{~h}$ & $\mathrm{CaCl}_{2} 3 \% 21 \mathrm{~h}$ & $8.3 \pm 0.9$ & $2.9 \pm 0.7$ & & $65.1 \pm 0.8$ \\
\hline
\end{tabular}

where $S$ is the shrinkage ratio, and $D_{\mathrm{b}}$ and $D_{\mathrm{a}}$ are the beads dimeter before and after drying respectively.

For non-spherical beads, three dimensions measured represent the length, the width, and the height of the studied beads. Then the mean value of the three measurements was used to calculate the shrinkage ratio.

\subsection{In vitro release study}

In vitro release of tiaprofenic acid from the beads were carried out in triplicate at room temperature applied for $200-300 \mathrm{mg}$ of dried beads. The dissolution media was $5 \mathrm{ml}$ (PBS, pH 7.4), with a gentle stirred for a period up to $6 \mathrm{~h}$. At pre-set intervals, $0.2 \mathrm{ml}$ of aliquot was withdrawn from release medium and the same volume of fresh medium was replenished immediately to keep the release medium at constant volume. The withdrawn aliquots were analyzed by chiral HPLC.

\subsection{Drug release kinetic modelling}

Five different models; zero-order, first-order, Higuchi, HixonCrowell and Korsmeyer-Peppas were investigated to simulate the release kinetic of both Tia enantiomers.

\section{Results and discussion}

\subsection{Beads characterization}

Beads shape and size differed depending on the beads type. $\mathrm{ACa}, \mathrm{AZn}$ and $\mathrm{ABa}$; the divalent ion metal beads (DivB) looked spherical or spherical-like with mean size of 5-7 $\mathrm{mm}$ for wet and $2-3 \mathrm{~mm}$ for dry. AFe and $\mathrm{AAl}$; the trivalent ion metal beads (TrivB) were not spherical they had tear-like, wrinkled, collapsed and twisted forms with mean size of 7-9 $\mathrm{mm}$ for wet and 2-3.5 $\mathrm{mm}$ for dry. However, DivB looked smaller than TrivB with relatively smaller shrinkage ratio. ACa beads showed smaller size and shrinkage ratio compared to those congealed with Fe simultaneously $\mathrm{A}_{1} \mathrm{~T}$, and consecutively $\mathrm{A}_{2} \mathrm{~T}$ and $\mathrm{A}_{3} \mathrm{~T}$. Table 1 presents some characteristics of the prepared beads; congealing conditions, bead size and shrinkage ratio.

$\mathrm{Na}$ content in the starting sodium alginate was determined to be $(0.39 \mathrm{~mol} / 100 \mathrm{~g})$. For DivB and TrivB, the metal content was smaller than $\mathrm{Na}$ content in the starting alginate with expected values of $(0.19 \mathrm{~mol} / 100 \mathrm{~g})$ and $(0.13 \mathrm{~mol} / 100 \mathrm{~g})$ respectively. These expected values come from the assumption

Table 2 Results for drug loading and loading efficiency of the Tia loaded beads ${ }^{a}$

\begin{tabular}{|c|c|c|c|c|c|c|c|c|}
\hline \multirow[b]{2}{*}{$\begin{array}{l}\text { Beads } \\
\text { name }\end{array}$} & \multicolumn{2}{|c|}{ Before congealing } & \multicolumn{4}{|c|}{ After congealing } & \multicolumn{2}{|l|}{ After drying } \\
\hline & $W_{\text {Alg }}(\mathrm{mg})$ & Tia, $W_{\mathrm{t}}(\mathrm{mg})$ & $\begin{array}{l}\text { Wet beads } \\
\text { weight }(\mathrm{g})\end{array}$ & Tia, $W_{\text {res }}(\mathrm{mg})$ & Tia, $W_{1}(\mathrm{mg})$ & Tia, $L \%$ & $\begin{array}{l}\text { Dry beads weight, } \\
W_{\mathrm{db}}(\mathrm{mg})\end{array}$ & Tia\% \\
\hline ACaT & $321 \pm 0.3$ & $83 \pm 0.4$ & $9.114 \pm 0.4$ & $0.41 \pm 1.1$ & $82.6 \pm 0.2$ & $99.4 \pm 0.1$ & $416 \pm 0.3$ & $20.3 \pm 0.6$ \\
\hline $\mathrm{ABaT}$ & $317 \pm 0.7$ & $81 \pm 0.1$ & $9.071 \pm 0.2$ & $7.13 \pm 0.3$ & $73.9 \pm 0.9$ & $91.2 \pm 0.6$ & $531 \pm 0.4$ & $13.9 \pm 0.4$ \\
\hline $\mathrm{AZnT}$ & $304 \pm 0.5$ & $81 \pm 0.2$ & $8.125 \pm 0.4$ & $6.82 \pm 0.7$ & $74.2 \pm 0.3$ & $91.6 \pm 0.4$ & $396 \pm 0.4$ & $18.7 \pm 0.5$ \\
\hline AAlT & $319 \pm 0.2$ & $82 \pm 0.5$ & $9.851 \pm 0.5$ & $8.50 \pm 0.9$ & $73.5 \pm 0.5$ & $89.6 \pm 0.5$ & $539 \pm 0.3$ & $13.6 \pm 0.4$ \\
\hline $\mathrm{AFeT}$ & $325 \pm 0.4$ & $83 \pm 0.4$ & $11.733 \pm 0.4$ & $0.30 \pm 0.4$ & $72.7 \pm 0.6$ & $87.6 \pm 0.4$ & $597 \pm 0.4$ & $12.2 \pm 0.5$ \\
\hline $\mathrm{A} 1 \mathrm{~T}$ & $314 \pm 0.7$ & $82 \pm 0.4$ & $10.725 \pm 0.3$ & $0.86 \pm 0.2$ & $81.1 \pm 0.1$ & $98.9 \pm 0.1$ & $757 \pm 0.2$ & $10.7 \pm 0.7$ \\
\hline $\mathrm{A} 2 \mathrm{~T}$ & $318 \pm 0.3$ & $84 \pm 0.3$ & $8.983 \pm 0.9$ & $23.09 \pm 1.4$ & $60.9 \pm 1.2$ & $72.5 \pm 1.4$ & $537 \pm 0.7$ & $11.3 \pm 0.4$ \\
\hline A3T & $316 \pm 0.6$ & $82 \pm 0.2$ & $11.372 \pm 0.4$ & $1.22 \pm 0.3$ & $80.8 \pm 0.4$ & $98.5 \pm 0.1$ & $605 \pm 0.1$ & $13.3 \pm 0.5$ \\
\hline
\end{tabular}

${ }^{a} W_{\text {Alg: }}$ the quantity of alginate used to form the $2 \%(\mathrm{w} / \mathrm{v})$ solution in PBS. 


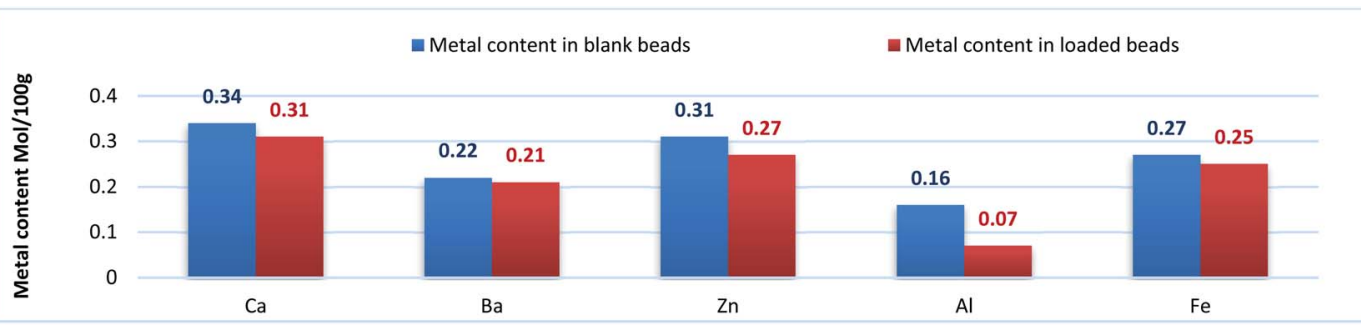

Fig. 3 Metal content (mol/100 g) for blank beads (blue column), and metal content for loaded beads (red column).

that the divalent and trivalent metal ions exchanges with $\mathrm{Na}$ during beads formation, hence the expected values are the results of dividing Na content by 2 for DivB and 3 for TrivB. However, the obtained values, as shown in Fig. 3, indicate higher contents than the expected ones, except the case of AAlT. Which may due to free ions did not form the egg-box but still entrapped in the resulted network when beads are wet, and consequently when beads dried. Moreover, the results suggest higher metal content for all blank beads in comparison to those loaded beads. Thus, may due to the entrapment of Tia inside the network, which subsequently limit the entrapment of free metal ions. The results also reveal that the metal contents follow the same order for loaded and blank beads, i.e. $\mathrm{Ca}>\mathrm{Zn}>\mathrm{Fe}>\mathrm{Ba}>\mathrm{Al}$.

The results obtained for drug content (Tia\%) and drug loading efficiency $(L \%)$ are shown in Table 2 . For DivB, Tia\% values varied from 13.9 for ABaT to 20.3 for ACaT, while TrivB gave 13.6 for AAlT which is comparable to 12.2 for AFeT. Practically, the lowest contents were for $A_{1} T, A_{2} T$, and $A_{3} T$.

\subsection{IR spectroscopy}

Interactions between entrapped Tia and alginate complexes can lead to identifiable changes in the FTIR spectra of loaded beads compared with blank beads. Thus, IR spectra were registered for all kinds of prepared beads. For further investigation, physical mixtures of Tia with blank beads were prepared and compared with IR spectra of blank and loaded Tia beads, Table 3 and Fig. 4-7 summaries the results.

The spectrum of Tia shows absorption bands at 2250$3250 \mathrm{~cm}^{-1}$ from carboxylic $\mathrm{OH}$, and stretching vibrations at (1741, 1602) $\mathrm{cm}^{-1}$ for $\mathrm{C}=\mathrm{O}$ carboxyl and $\mathrm{C}=\mathrm{O}$ ketone respectively.

Table 3 IR data for analyzed substances in view of expected interactions

\begin{tabular}{|c|c|c|c|c|c|}
\hline & OH hydroxyl & OH carboxyl & $\mathrm{C}=\mathrm{O}$ carboxyl Tia & $\mathrm{C}=\mathrm{O}$ carboxyl Alg & $\begin{array}{l}\mathrm{C}=\mathrm{O} \\
\text { ketone Tia }\end{array}$ \\
\hline Tia & & $\underset{a}{2250-3250}$ & 1741 & acro & 1602 \\
\hline \multicolumn{6}{|c|}{ Blank beads } \\
\hline $\mathrm{ACa}$ & 3434 & $a$ & & $1636(1500-1800)$ & \\
\hline AAl & $3419(3000-3750)$ & $a$ & & $1629(1500-1800)$ & \\
\hline $\mathrm{AFe}$ & 3416 & $a$ & & 1632 & \\
\hline \multicolumn{6}{|c|}{ Loaded beads } \\
\hline $\mathrm{ACaT}$ & $3489,3000-3750$ & 1734 & 1641 & 1608 & \\
\hline $\mathrm{ABaT}$ & $3000-3750$ & OV (1500-2000) & OV (1500-1800) & 1602 & \\
\hline \multicolumn{6}{|c|}{ Physical mixture } \\
\hline ANa-T & $3151(3750-2400)$ & 1734 & OV (1500-1800) & 1602 & \\
\hline $\mathrm{ACa}-\mathrm{T}$ & $3420,2500-3750$ & 1739 & $1628(1500-1800)$ & 1606 & \\
\hline $\mathrm{ABa}-\mathrm{T}$ & $2000-3750$ & 1734 & OV $(1500-1800)$ & 1602 & \\
\hline$A Z n-T$ & $2700-3750$ & 1734 & $1626(1500-1800)$ & 1606 & \\
\hline $\mathrm{AFe}-\mathrm{T}$ & $3396,2500-3750$ & 1739 & 1627 & OV (1500-1800) & \\
\hline AAl-T & $2300-3750$ & 1739 & OV (1500-1800) & 1611 & \\
\hline
\end{tabular}

${ }^{a}$ Carboxylic $\mathrm{OH}$ of alginate metal complexes is not expected because the proton $\mathrm{OH}$ is replaced with the ion metal making an overall broad signal of hydroxyl OH. OV: the corresponding signal is not resolved but overlapped with other signal in the determined range below. 

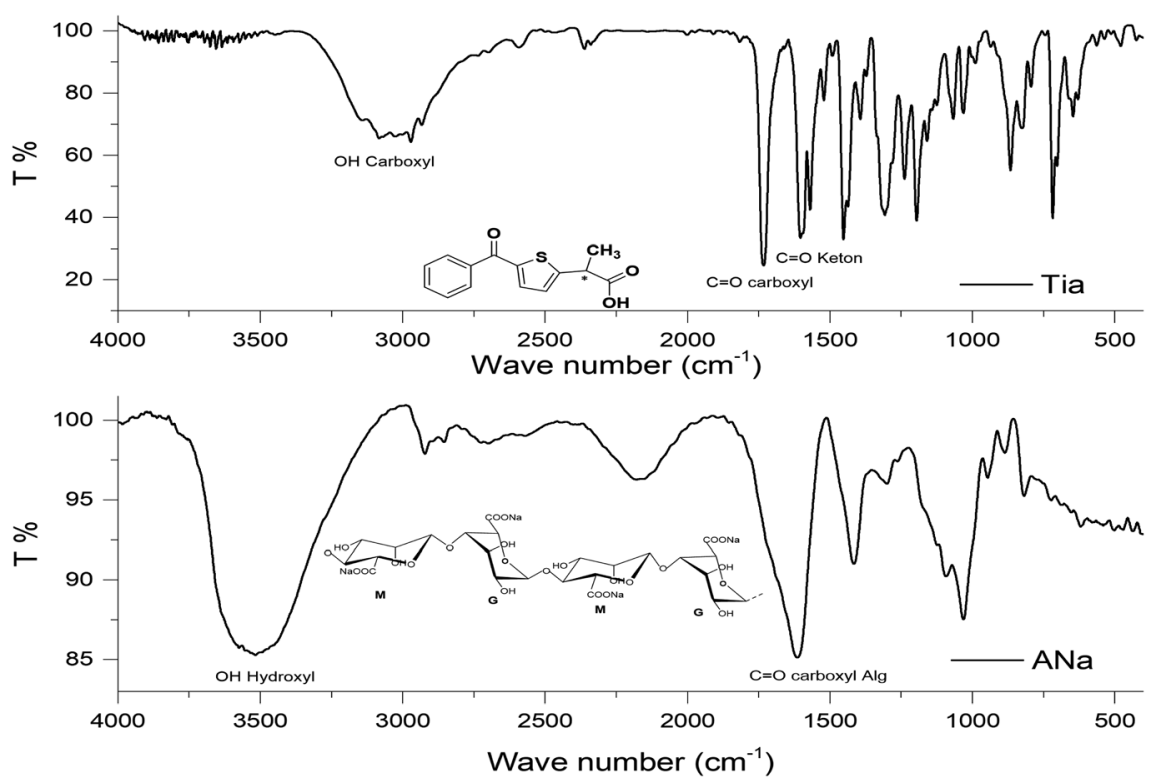

Fig. 4 IR spectra of ANa and Tia.

Prepared alginate beads, shows small shift (about 10$15 \mathrm{~cm}^{-1}$ ) of $\mathrm{C}=\mathrm{O}$ stretching vibration higher wavenumber compared to initial ANa in the region of $1622 \mathrm{~cm}^{-1}$. Generally, a broad absorption band for $\mathrm{OH}$ in the region $3000-3750 \mathrm{~cm}^{-1}$.

Alginate loaded beads show IR spectra similar to those of blank beads. However, some variation can be noticed for the spectra of AZnT, AAlT and AFeT in the region of $\mathrm{C}=\mathrm{O}$ belongs to Tia where the corresponding band appeared at 1734, 1733, and $1741 \mathrm{~cm}^{-1}$ respectively.

In the case of physical mixtures of Tia and bank beads, an overlapping for alginic $\mathrm{C}=\mathrm{O}$ band was noticed with the $\mathrm{C}=\mathrm{O}$ band of Tia. On the other hand, a very strong band of Tia
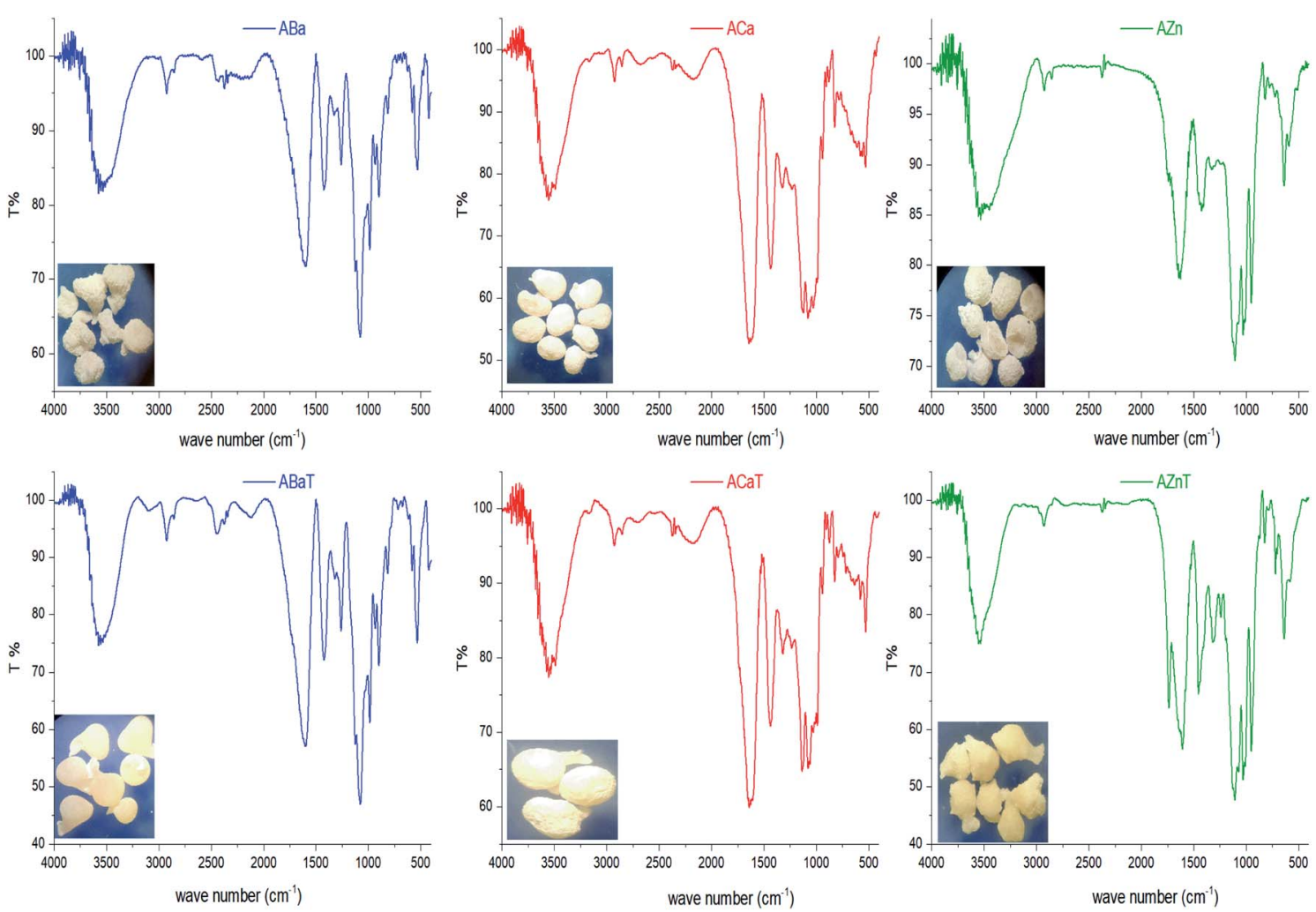

Fig. 5 IR spectra of blank and loaded alginate divalent metal complexes. 

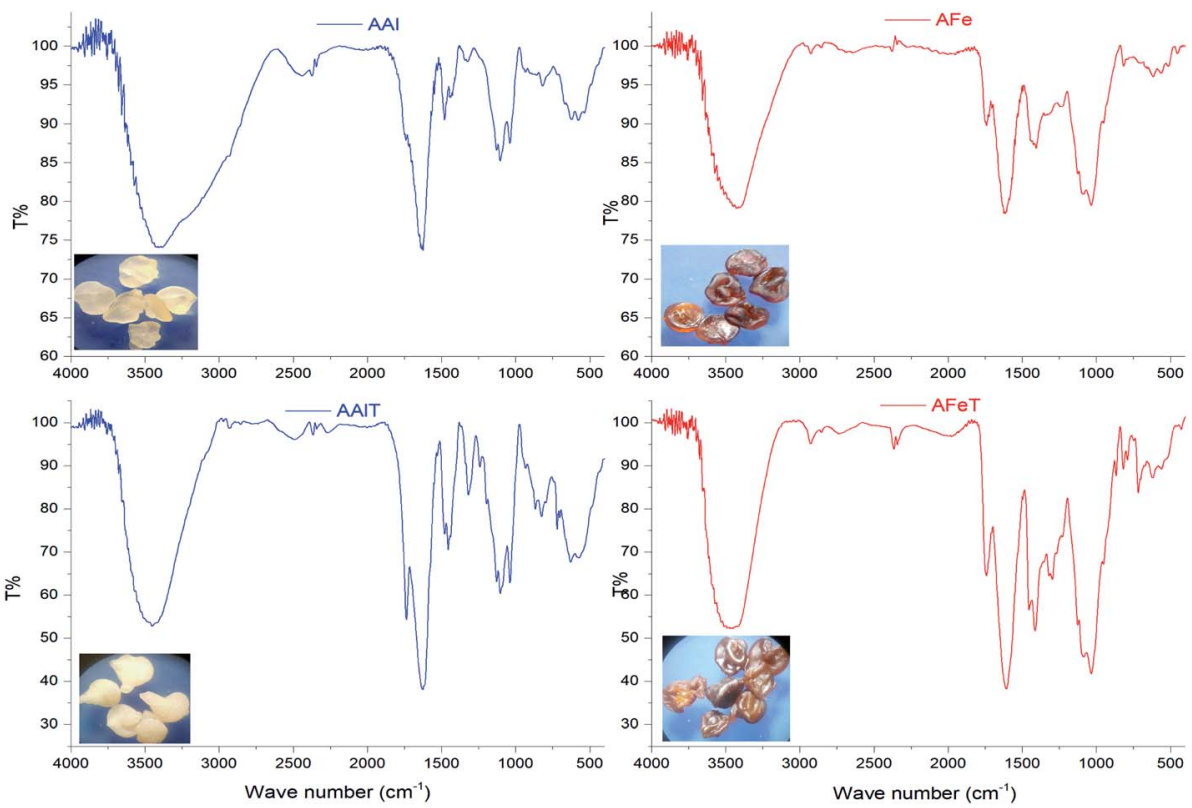

Fig. 6 IR spectra of blank and loaded alginate trivalent metal complexes.

hydroxyl (2250-3250 $\left.\mathrm{cm}^{-1}\right)$ beside of alginate complexes $\left(3250-3750 \mathrm{~cm}^{-1}\right)$ led to wide band in the region 2000$3750 \mathrm{~cm}^{-1}$.

Spectra comparison led to the conclusion that there was not any chemical reaction between Tia and alginate complexes during the preparation of alginate beads, while a physical interaction was observed via hydrogen bonding between $\mathrm{C}=\mathrm{O}$ carboxyl, $\mathrm{C}=\mathrm{O}$ ketone and carboxylic $\mathrm{OH}$ of Tia and the carboxyl and the hydroxyl groups of alginate. The $\mathrm{OH}$ signals for Tia carboxylic $\mathrm{OH}$ and alginate hydroxylic $\mathrm{OH}$ became one signal due to the hydrogen bonding interaction. The aforementioned results led to chiral interaction suggestions that can explain the enantioselective release during release experiments.

\subsection{In vitro tiaprofenic acid enantiomers release study}

3.3.1. Enantioselective release investigation. The chiral interaction suggested by the results of IR spectroscopy, can be investigated by studying the release behavior in a chosen release medium. To monitor the enantioselective release, the chromatographic area ratio of $R$ to $S$ enantiomers was used as ESR $=$ $R / S$. In parallel, the enantiomeric excess ee\% $=|(R-S) /(R+S)|$ $\times 100$ was calculated, as the concentration of each enantiomer in the release medium is directly proportional to the corresponding chromatographic area. Typical chromatograms for the released beads; blank and loaded, are presented in the Fig. 8. The obtained results for ESR and ee\% are shown in Fig. 9 and Table 4 respectively, for an experiment time of $300 \mathrm{~min}$. DivB showed higher values for ESR and ee\% compared to those
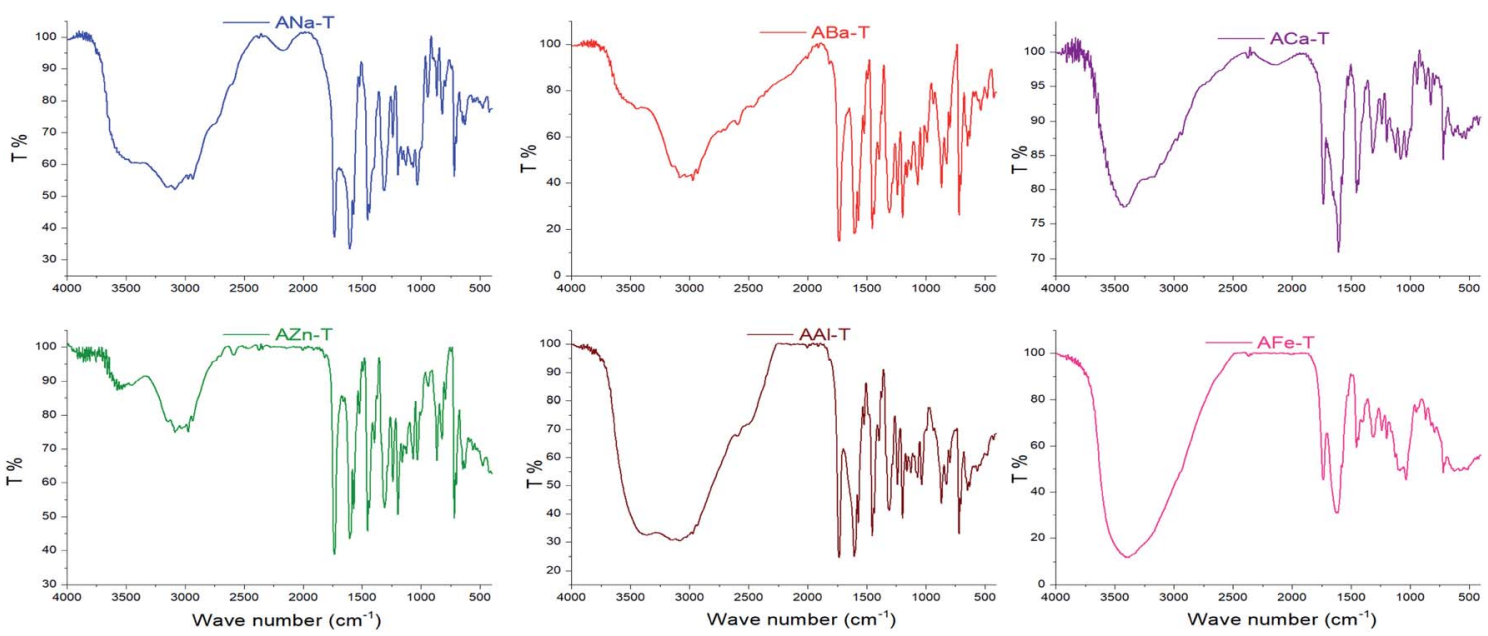

Fig. 7 IR spectra of physical mix of tiaprofenic acid with blank beads. 


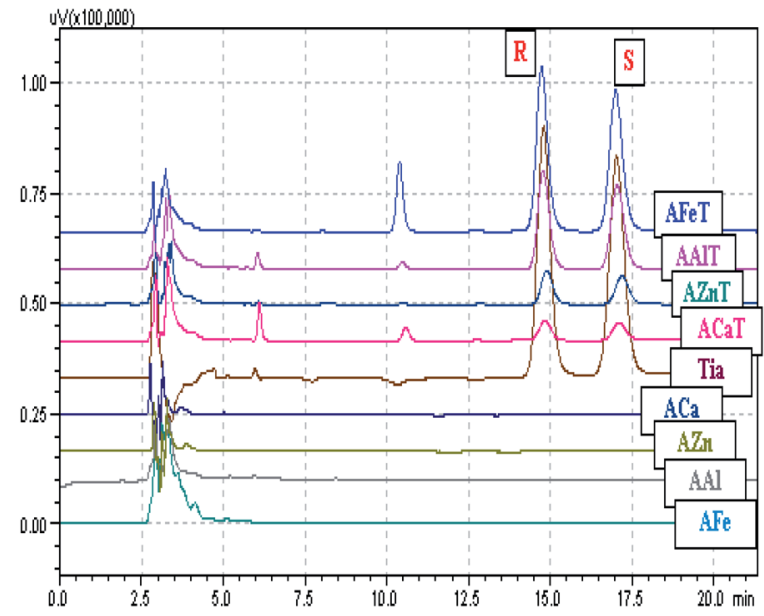

Fig. 8 Typical chromatograms for the released enantiomers $R$ and $S$ of Tia from DivB and TrivB are obtained using chiral HPLC. From the top; AFeT, AAIT, AZnT and ACaT: the chromatograms relevant to loaded beads. Tia: a reference chromatogram of Tia. ACa, AZn, AAl and AFe are the chromatograms corresponding to blank beads.

of TrivB. ACaT and AZnT beads started to release the enantiomer $R$ selectively, however, the release became less stereoselective when ESR approaches to 1 and ee\% approaches to $0 \%$. Because of the very weak release of Tia enantiomers from ABaT beads, ESR values fluctuates strongly and thus ee\% values are not shown in Table 4 . TrivB did not show a noticed stereoselective release as ESR and ee\% values are close to 1 and $0 \%$ respectively. Thus, Tia reacts more stereoselectivity with the network formed in DivB complexes leading to remarkable stereoselective release comparing to the case of TrivB. The
Table 4 Obtained \% ee results in the release medium

\begin{tabular}{lllll}
\hline Time & ACaT & AZnT & AFeT & AAlT \\
\hline 10 & $10.9(R) \pm 0.4$ & $16.7(R) \pm 0.1$ & $1.0(R) \pm 0.1$ & $1.6(R) \pm 0.4$ \\
20 & $2.0(R) \pm 0.2$ & $10.7(R) \pm 0.1$ & $1.2(R) \pm 0.1$ & $0.2(R) \pm 0.3$ \\
30 & $2.6(R) \pm 0.4$ & $6.9(R) \pm 0.1$ & $0.5(S) \pm 0.2$ & $0.1(R) \pm 0.3$ \\
40 & $1.6(R) \pm 0.3$ & $7.1(R) \pm 0.1$ & $0.4(R) \pm 0.1$ & $0.2(S) \pm 0.3$ \\
50 & $1.6(R) \pm 0.6$ & $6.9(R) \pm 0.1$ & $0.2(R) \pm 0.2$ & $0.5(S) \pm 0.4$ \\
60 & $2.0(R) \pm 0.4$ & $7.7(R) \pm 0.1$ & $0.8(R) \pm 0.2$ & $0.5(S) \pm 0.4$ \\
75 & $2.8(R) \pm 0.1$ & $3.6(R) \pm 0.1$ & $0.1(S) \pm 0.2$ & $0.5(S) \pm 0.3$ \\
90 & $1.4(R) \pm 0.2$ & $4.1(R) \pm 0.1$ & $0.2(S) \pm 0.2$ & $0.5(S) \pm 0.3$ \\
120 & $1.5(R) \pm 0.4$ & $1.7(R) \pm 0.2$ & $0.3(S) \pm 0.2$ & $0.4(S) \pm 0.4$ \\
150 & $1.5(R) \pm 0.4$ & $2.8(R) \pm 0.2$ & $0.6(S) \pm 0.2$ & $0.3(S) \pm 0.4$ \\
210 & $2.3(R) \pm 0.4$ & $2.3(R) \pm 0.2$ & $0.7(S) \pm 0.2$ & $0.1(S) \pm 0.4$ \\
300 & $2.1(R) \pm 0.4$ & $0.5(R) \pm 0.2$ & $0.9(S) \pm 0.3$ & $0.3(S) \pm 0.4$
\end{tabular}

nature of the egg-box structure of the network plays a key role in this stereoselective interactions.

Alginates beads, congealed with two metals, Fe and $\mathrm{Ca}$, showed different behaviors. As presented in Fig. 10, in the case of simultaneous congealing beads $\mathrm{A}_{1} \mathrm{~T}$, ESR values were practically 1 all over the experiment time. However, for consecutively congealed beads $\mathrm{A}_{2} \mathrm{~T}$ and $\mathrm{A}_{3} \mathrm{~T}$, ESR values were higher in the first $30 \mathrm{~min}$ of the experiment. Thereafter, ESR behaved in a similar fashion to that in $\mathrm{A}_{1} \mathrm{~T}$.

3.3.2. Simulating the release kinetic of Tia enantiomers. ESR and ee\% values indicated an enantioselective release in case of ACaT and AZnT, but less important in case of AFeT and AAlT. Kinetic simulation aims to investigate the effect of chiral interactions on the release kinetic of each enantiomer. In other words, the chiral interactions, visualized by ESR and ee\%, may
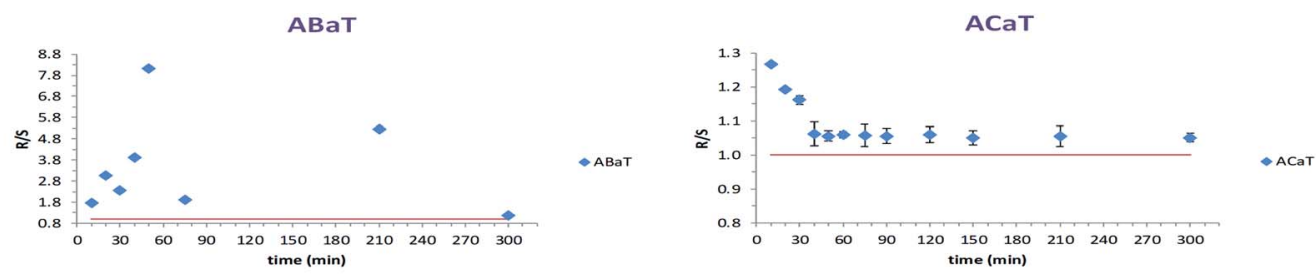

AZnT
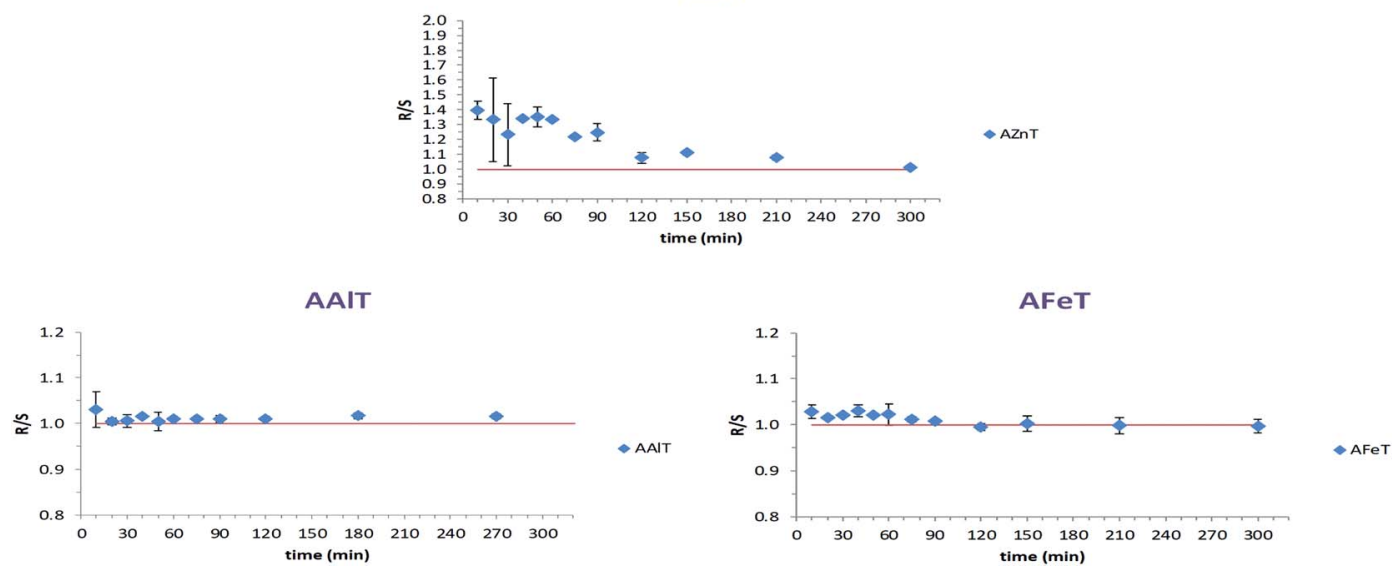

Fig. 9 ESR for DivB and TrivB monitored by chiral HPLC as R/S ratio. 

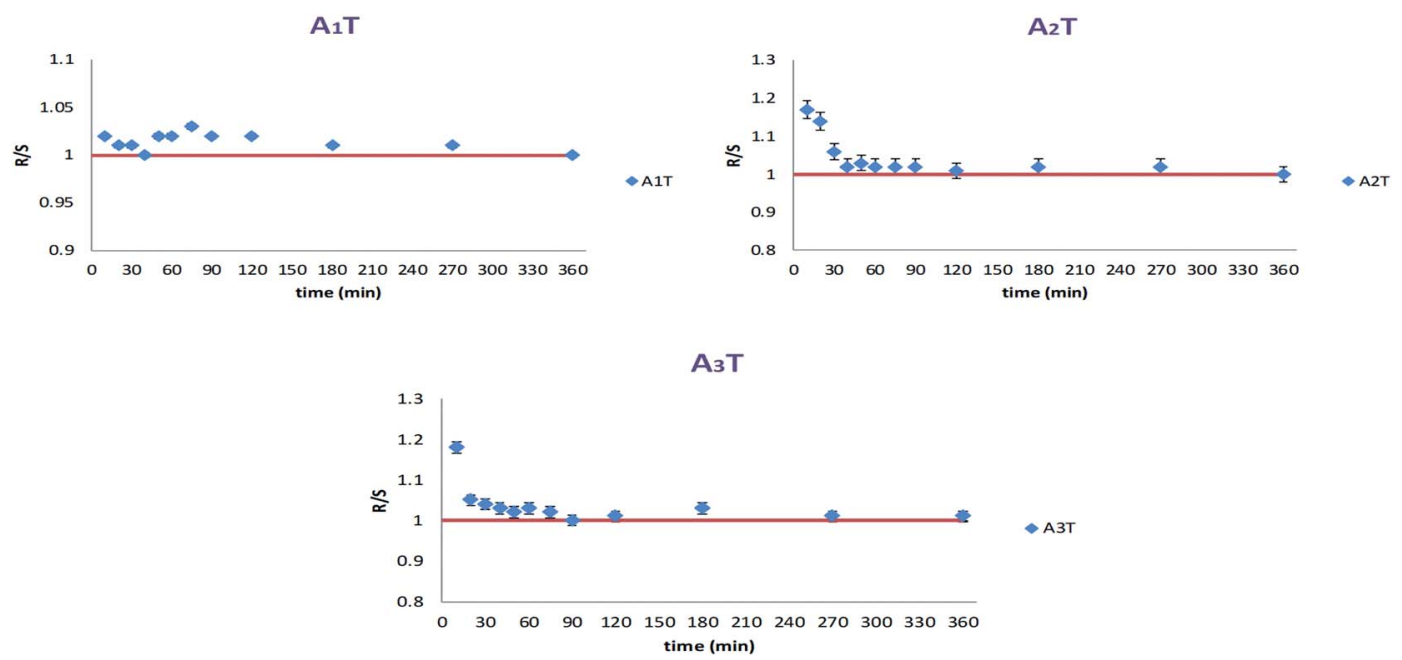

Fig. 10 ESR for simultaneously $\left(A_{1} T\right)$ and consecutively $\left(A_{2} T\right.$ and $\left.A_{3} T\right)$ congealed beads.

lead to different release mechanisms and hence different kinetics.

The concentration $\left(\mu \mathrm{g} \mathrm{ml}^{-1}\right)$ of each enantiomer was plotted against time (hours), bearing in mind that the release medium volume was conserved. Fig. 11 presents the obtained curves for each enantiomer released from the studied beads ACaT, AZnT, $\mathrm{AFeT}$ and AAlT. In the case of AAIT and AFeT the obtained curves for $S$ and $R$ enantiomers are practically superimposed because of the minor values of ESR and ee\%. However, curves are more distinguishable in the case of ACaT and AZnT. Moreover, the curves behaved differently depending on the metalcomplex. For TrivB, AAlT released much more Tia enantiomers than AFeT all over the experiment time. As shown in
Fig. 11, enantiomers concentrations are $\sim 8 \mu \mathrm{g} \mathrm{ml} \mathrm{m}^{-1}$ and $\sim 2 \mu \mathrm{g}$ $\mathrm{ml}^{-1}$ for AAlT and AFeT, respectively, at the first hour, and they became $\sim 11 \mu \mathrm{g} \mathrm{ml}^{-1}$ and $\sim 3 \mu \mathrm{g} \mathrm{ml}^{-1}$ at the fifth hour. For DivB, ACaT curves showed different behavior from those of AZnT; the enantiomers, approximately, reached maximum concentrations after one hour, while enantiomers released gradually from AZnT to reach the maximum after five hours. Thus, five kinetic models; zero-order, first-order, Higuchi, Hixson-Crowell and Korsmeyer-Peppas, were used to simulate the release kinetics of Tia enantiomers.

Table 5 summarizes the resulted correlation coefficient $R^{2}$ and the release kinetic constant corresponding to each studied model. The obtained values for ACaT, shows that $R$

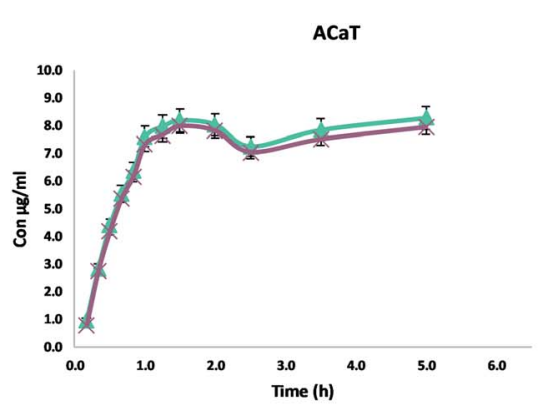

A

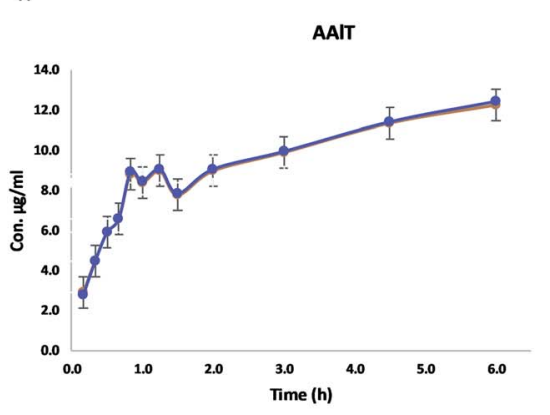

c
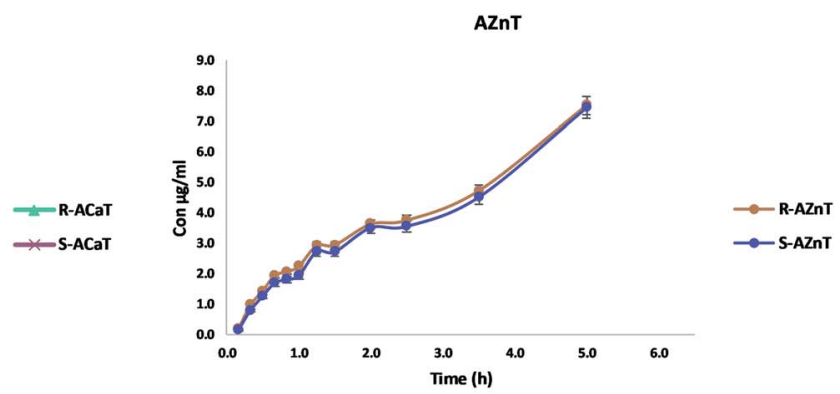

B
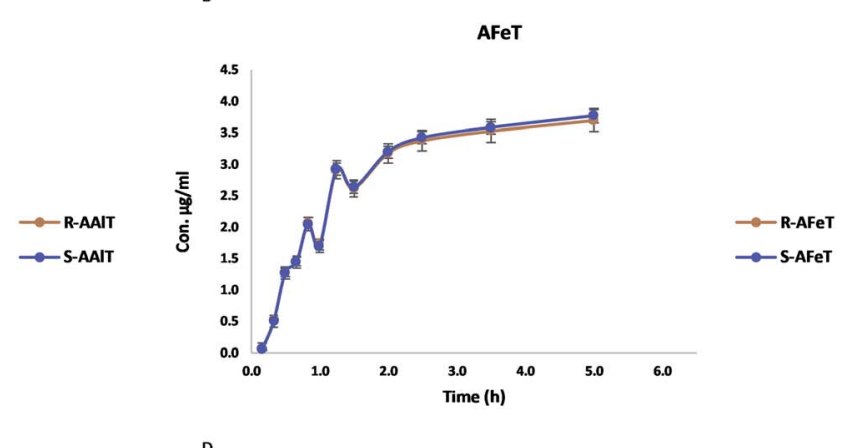

D

Fig. 11 Release behavior of Tia enantiomers, (A) ACaT, (B) AZnT, (C) AAIT, (D) AFeT monitored by chiral HPLC. 
Table 5 Results of correlation coefficient $R^{2}$ and the release kinetic constant for each studied model

\begin{tabular}{|c|c|c|c|c|c|c|c|c|c|c|c|}
\hline \multirow[b]{2}{*}{ Beads } & \multirow[b]{2}{*}{ Released enantiomer } & \multicolumn{2}{|c|}{ Zero order } & \multicolumn{2}{|c|}{ First order } & \multicolumn{2}{|c|}{ Higuchi } & \multicolumn{2}{|c|}{ Hixson-Crowell } & \multicolumn{2}{|c|}{$\begin{array}{l}\text { Korsmeyer- } \\
\text { Peppas }\end{array}$} \\
\hline & & $R^{2}$ & $K_{0}$ & $R^{2}$ & $K_{1}$ & $R^{2}$ & $K_{\mathrm{H}}$ & $R^{2}$ & $K_{\mathrm{HC}}$ & $R^{2}$ & $n$ \\
\hline \multirow[t]{2}{*}{$\mathrm{ACaT}$} & $R$ & 0.845 & 0.016 & 0.860 & $-7 \times 10^{-5}$ & 0.924 & 0.048 & 0.006 & -0.0001 & 0.942 & 0.279 \\
\hline & $S$ & 0.852 & 0.014 & 0.852 & $-6 \times 10^{-5}$ & 0.930 & 0.043 & 0.006 & -0.0005 & 0.936 & 0.264 \\
\hline \multirow[t]{2}{*}{$\mathrm{AZnT}$} & $R$ & 0.969 & 0.011 & 0.969 & $-5 \times 10^{-5}$ & 0.937 & 0.033 & 0.946 & -0.002 & 0.969 & 0.623 \\
\hline & $S$ & 0.966 & 0.012 & 0.966 & $-5 \times 10^{-5}$ & 0.934 & 0.034 & 0.946 & -0.002 & 0.969 & 0.686 \\
\hline \multirow[t]{2}{*}{ AAlT } & $R$ & 0.953 & 0.031 & 0.953 & -0.0001 & 0.984 & 0.101 & 0.795 & -0.002 & 0.973 & 0.308 \\
\hline & $S$ & 0.954 & 0.032 & 0.954 & -0.0001 & 0.985 & 0.102 & 0.788 & -0.002 & 0.975 & 0.308 \\
\hline \multirow[t]{2}{*}{$\mathrm{AFeT}$} & $R$ & 0.914 & 0.031 & 0.915 & -0.0001 & 0.972 & 0.091 & 0.657 & -0.001 & 0.942 & 0.733 \\
\hline & $S$ & 0.915 & 0.031 & 0.915 & -0.0001 & 0.972 & 0.092 & 0.669 & -0.001 & 0.941 & 0.741 \\
\hline
\end{tabular}

and $S$ enantiomer released from the beads according to the best fit model of Korsmeyer-Peppas. However, values obtained for each enantiomer in the case of AZnT did not result in a clear best fit model; zero-order, first-order, and Korsmeyer-Peppas models are all compatible because of $R^{2}=$ 0.969 (for $R$ enantiomer) and $R^{2}=0.966$ (for $S$ enantiomer). Higuchi model was the best fit model in the case of TrivB for both enantiomers, where, the correlation coefficient was 0.972 and 0.985 for AFeT and AAlT respectively. It is wellknown that several factors affect drug release like physicochemical properties of drug, excipient and dosage form design. Release kinetic of a drug is also influenced by other factors; surface area change, pore size, swelling and nonswelling properties of matrix elements and drug content and drug concentration profile in the matrix. The common used models to simulate drug release, such as those used in the manuscript, deals with defined dosage forms i.e. cylindrical, spheres, tablets, patches, ... etc ${ }^{\mathbf{1 9}}$. In fact, the prepared beads, described in the manuscript, differ from those forms mentioned above and they have some particularities: they are not ideal spheres and differ from each other in surface description. The drug content varies depending on the complex type (Table 2) and the drug concentration profile is unknown. The cation size and the cross-linking properties are not the same in all beads kinds. Beads homogeneity is unknown. In brief, the properties of the resulted cross-linked networks with "egg-box" structures vary depending on the properties of the metal ion. Subsequently, surface and core morphologies vary along with physicochemical properties. This could lead to different interactions with the drug and different release mechanisms. The reported exponent $n$ values (Table 5) indicate quasi-Fickian diffusion $(n<0.5)$ for ACaT and AAlT cases and non-Fickian mechanism for AZnT and AFeT cases $(0.5<n<1)$.

\section{Conclusions}

Chiral interactions between tiaprofenic acid and alginatemetal-complexes were investigated using IR spectroscopy, and visualized using chiral HPLC in terms of ESR and ee\%. The obtained values of ESR and ee\% indicated notable interactions in the case of ACaT and AZnT, but less important in the case of AAlT and AFeT. The concentrations of $R$ and $S$ enantiomers during the release experiment showed different behaviors for the different beads. Thus, the release kinetic was simulated for each enantiomer from the studied beads. Enantiomers showed the same best fit models for the same studied beads. However, the obtained models for DivB were different from those of TrivB. Interestingly, the case of AZnT resulted in three probable models as the corresponding correlation coefficient values are the same. This case implies further investigation to understand the release mechanism. It can be concluded also that the nature of "egg-box", which depends on the metal ion, plays a substantial role on the possible chiral interactions between the drug and the alginate complex.

\section{Conflicts of interest}

There are no conflicts to declare.

\section{Acknowledgements}

The authors would like to thank the Department of Chemistry, University of Damascus, and the Higher Institute of Applied Sciences and Technology for providing the assistance needed to complete the experiments.

\section{References}

1 I. K. Reddy and R. Mehva, Chirality in Drug Design and Development, USA, 2004.

2 N. Ananthi, Organic \& Medicinal Chemistry International Journal, 2018, 5, 1-6.

3 H. Yu, X. Yong, J. Liang, J. Deng and Y. Wu, Ind. Eng. Chem. Res., 2016, 55, 6037-6048.

4 M. C. Gohel, Dissolution Technol., 2003, 10, 16-20.

5 S. J. Mohan, E. C. Mohan and M. R. Yamsani, Int. J. Pharm. Sci. Nanotechnol., 2009, 1, 309-316.

6 A. Calcaterra and I. D'Acquarica, J. Pharm. Biomed. Anal., 2018, 147, 323-340.

7 R. C. Rowe, P. J. Sheskey and M. E. Quinn, Handbook of Pharmaceutical Excipients, Pharmaceutical Press and American Pharmacists Association, USA, 6th edn, 2009. 
8 M. S. Hasnain and A. K. Nayak, Alginates Versatile, Versatile Polymers in Biomedical Applications and Therapeutics, 2019, vol. 53.

9 M. Szekalska, A. Puciłowska, E. Szymańska, P. Ciosek and K. Winnicka, Int. J. Polym. Sci., 2016, 2016, 1-18.

10 B. H. A. Rehm, Alginates: Biology and Applications, 2006, vol. 13.

11 K. Baxter, K. Aikman, A. Brayfield, R. Buckingham, C. Cadart, M. Harrison, H. Hayne, M. A. Daya, H. Arnold, N. Bell-Asher, L. C. Sáez, R. Chin, K. Eager, E. Henderson, S. Ho, E. King, S. Ladani, D. Lipanovic, J. MacKershan, J. Martin, A. McFarlane, D. McGuirk, BNF 79, BMA-Royal pharmaceutical society, UK, 79th edn, 2020, vol. March-Sep. 12 N. M. Davies, Clin. Pharmacokinet., 1996, 31, 331-347.
13 M. Vakily and F. Jama, J. Pharm. Sci., 1994, 83, 495-498.

14 P. Patil, D. Chavanke and M. Wagh, Int. J. Pharm. Pharm. Sci., 2012, 4, 27-32.

15 M. Christianah Adeyeye, in Chirality in Drug Design and Development, 2004.

16 L. Li, Y. Fang, R. Vreeker, I. Appelqvist and E. Mendes, Biomacromolecules, 2007, 8, 464-468.

17 A. M. du Poset, A. Zitolo, F. Cousin, A. Assifaoui and A. Lerbret, Phys. Chem. Chem. Phys., 2020, 22, 2963-2977.

18 G. Alkhayer, H. Khudr and Y. Koudsi, Anal. Bioanal. Chem. Res., 2020, 7, 61-76.

19 M. P. Paarakh, P. A. N. I. Jose, C. M. Setty and G. V. Peter, International Journal of Pharmacy Research \& Technology, 2018, 8, 12-20. 